\title{
PYGB siRNA inhibits the cell proliferation of human osteosarcoma cell lines
}

\author{
SHUWEI ZHANG, YICHI ZHOU, YUANYU ZHA, YANG YANG, LINLONG WANG，JINGFENG LI and WEI JIN \\ Department of Orthopedics, Zhongnan Hospital of Wuhan University, Wuhan, Hubei 430071, P.R. China
}

Received December 22, 2016; Accepted January 17, 2018

DOI: $10.3892 / \mathrm{mmr} .2018 .9022$

\begin{abstract}
Osteosarcoma is the most common malignant bone carcinoma that primarily occurs between childhood to adolescence. It was suggested by recent research that the Brain type glycogen phosphorylase (PYGB) gene may serve an important role in various types of cancer. In the present study, the PYGB gene was knocked down in order to evaluate the cell viability, invasion and migration of the human osteosarcoma cell lines MG63 and HOS. The expression levels of PYGB in osteosarcoma and bone cyst tissue samples, as well as in the osteosarcoma cell lines were identified using reverse transcription-quantitative polymerase chain reaction and western blot assay. Subsequently, a Cell Counting kit 8 assay was employed to evaluate cell proliferation. Cell apoptosis rate and cell cycle distribution were measured by flow cytometry. In addition, cell invasion and migration were evaluated through a Transwell assay. The expression levels of the cell apoptosis and tumor metastasis associated proteins B-cell lymphoma 2 (Bcl-2), Bcl-2-associated X protein, E-cadherin, Twist, matrix metalloproteinase (MMP)-9 and MMP2 were measured via western blotting. PYGB exhibited a higher expression level in the osteosarcoma tissue samples, particularly in the human osteosarcoma cell lines MG63 and HOS. Knockdown of PYGB resulted in a decline in cell proliferation, invasion and migration, which was coupled with induced cell apoptosis and cell cycle arrest in MG63 and HOS cells. Furthermore, alterations in the expression of apoptosis and metastasis associated proteins indicated that small interfering (si)PYGB may have regulated cell viability by targeting the $\mathrm{Bcl} / \mathrm{Caspase}$ and cyclin dependent kinase (CDK)-1 signaling pathway. In conclusion, PYGB siRNA exerted an inhibitory effect on the cell viability of the human osteosarcoma cells MG63 and HOS by blocking
\end{abstract}

Correspondence to: Dr Wei Jin or Dr Jingfeng Li, Department of Orthopedics, Zhongnan Hospital of Wuhan University, 169 Donghu Road, Wuhan, Hubei 430071, P.R. China

E-mail: zhangh160311@163.com

E-mail: hbjfeng@163.com

Key words: osteosarcoma, brain type glycogen phosphorylase small interfering RNA, cell cycle, metastasis the Caspase/Bcl and CDK1 signaling pathway, highlighting novel potential therapeutic methods for treating osteosarcoma.

\section{Introduction}

Bone cysts and osteosarcoma are tumor-like lesions of the bone. Bone cysts are mainly treated with surgery, which is associated with good prognosis; however, osteosarcoma is the most common malignant bone tumor that has poor prognosis, often resulting in metastatic disease (1-3). It represents $15 \%$ of all primary bone tumors and $0.2 \%$ of all malignant tumors in children and young adults (4-7). Currently, the main treatment for osteosarcoma is primary surgical control combined with systemic chemotherapy. Although the 5-year survival rate in patients with localized osteosarcoma is improved to $\sim 60 \%$ with this treatment, it is difficult for patients with osteosarcoma at advanced stage to be cured $(8,9)$.

Brain type glycogen phosphorylase (PYGB), which is encoded by the PYGB gene, catalyzes the rate-determining step in glycogen degradation $(10,11)$. It is upregulated by adenosine monophosphate, and downregulated by adenosine triphosphate and adenosine diphosphate $(12,13)$. Previous studies reported that PYGB was overexpressed in various types of cancers, including colorectal, gastrointestinal and non-small cell lung cancer (14-16). Due to the positive regulation of PYGB during the transitional process of adenoma cells to carcinoma cells, PYGB may be a useful biomarker to detect malignancy potential in precancerous lesions. Thus, the present study attempted to explore the role served by the PYGB gene in human osteosarcoma in order to identify a potential molecular marker for early diagnosis and treatment in clinical practice.

In the present study, the human osteosarcoma cell lines MG63 and HOS, with overexpressed PYGB, were transfected with PYGB small interfering (si)RNA. MG63 and HOS with PYGB knocked down were evaluated for cell proliferation, cell apoptosis, cell cycle distribution, invasion, migration and associated protein expression. The aim of the present study was to investigate the role of PYGB in the progression of osteosarcoma and explore novel therapeutic methods for the treatment of osteosarcoma.

\section{Materials and methods}

Tissue samples collection. Between January 2014 to December 2014, 15 patients with bone cysts (9 males and 
7 females, age range: $5-59$ years) and 35 patients with osteosarcoma (20 males and 15 females, age range: 8-55 years) were enrolled in the present study. The exclusion criteria were bone metastasis, rheumatoid arthritis and unwillingness to participate in the study. The study protocol was approved by the independent Ethical Committee of Zhongnan Hospital of Wuhan University (Hubei, China) and written informed consent was obtained from all participants. The bone cysts or osteosarcoma tissues were collected from all participants during routine surgery at Zhongnan Hospital of Wuhan University and kept at $-80^{\circ} \mathrm{C}$ until use.

Cell culture and transfection. MG63, HOS, U-20S, SaoS-2 and SW1353 cells were obtained from the Cell Bank of Type Culture Collection of Chinese Academy of Sciences (Shanghai, China). All the cell lines were cultured in Dulbecco's modified Eagle's medium (DMEM; Hyclone; GE Healthcare Life Sciences, Logan, UT, USA) containing $10 \%$ fetal calf serum (Thermo Fisher Scientific, Inc., Waltham, MA, USA) and 1\% 100X mycillin in $5 \% \mathrm{CO}_{2}$ at $37^{\circ} \mathrm{C}$. Cell viability was evaluated by trypan blue staining at room temperature for $1 \mathrm{~min}$ and observed using a light microscope (Olympus Corporation, Tokyo, Japan) when the cells reached $90 \%$ confluence. Cells with $95 \%$ cell viability were digested with $0.25 \%$ trypsin (Beijing Solarbio Science \& Technology Co., Ltd.) and seeded into 6 -well plates $\left(5 \times 10^{5}\right.$ cells/well) prior to transfection. A total of 3 PYGB siRNAs (Shanghai Genepharma, Co., Ltd., Shanghai, China) with different interference sites and control siRNA (NC; Shanghai Genepharma, Co., Ltd.) were used for transfection (Table I). Lipofectamine 2000 ${ }^{\mathrm{TM}}$ (Invitrogen; Thermo Fisher Scientific, Inc., Waltham, MA, USA) was used to transfect $5 \mu 1$ PYGB siRNA or NC siRNA into MG63 and HOS cells. Cells without any treatment were served as a Control cells. At $48 \mathrm{~h}$ following transfection, gene knockdown was confirmed by western blotting as described below. Cells with the PYGB gene knocked down were collected for subsequent experiments.

Reverse transcription-quantitative polymerase chain reaction (RT-qPCR) analysis. The mRNA expression of PYGB in the 50 tissue samples and the cell lines was measured by RT-qPCR. TRIzol reagent (Invitrogen; Thermo Fisher Scientific, Inc.) was used to extract and quantify total RNA from tissue samples or cultured cells. A Revert-aid reverse transcription kit (Fermentas; Thermo Fisher Scientific, Inc., Pittsburgh, PA, USA) and a SYBR-Green PCR kit (Fermentas; Thermo Fisher Scientific, Inc.) were used to perform RT-qPCR according to the manufacturer's protocol. The temperature protocol for RT was as follows: $37^{\circ} \mathrm{C}$ for $60 \mathrm{~min}, 85^{\circ} \mathrm{C}$ for $5 \mathrm{~min}$ and $4^{\circ} \mathrm{C}$ for $5 \mathrm{~min}$. The thermocycling conditions for qPCR were as follows: $95^{\circ} \mathrm{C}$ for 10 min followed by 40 cycles of $95^{\circ} \mathrm{C}$ for $15 \mathrm{sec}$ and $60^{\circ} \mathrm{C}$ for $45 \mathrm{sec}$. Table II presents the primers used for the amplification of PYGB and the reference gene, GAPDH. Quantification was performed using the $2^{-\Delta \Delta \mathrm{Cq}}$ method as previously described (17).

Western blot assay. Transfected cells were washed twice with 1X PBS, followed by radioimmunoprecipitation assay lysis buffer (Beijing Solarbio Science \& Technology Co., Ltd.) containing a $0.01 \%$ protease inhibitor cocktail (Sigma-Aldrich;
Table I. Sequences of the 3 interference sites of Brain type glycogen phosphorylase small interfering RNA.

\begin{tabular}{lll}
\hline $\begin{array}{l}\text { Interference } \\
\text { site }\end{array}$ & $\begin{array}{c}\text { Position } \\
(\mathrm{bp})\end{array}$ & \multicolumn{1}{c}{ Sequence (5'-3') } \\
\hline 1 & $941-963$ & GGUCCUGUAUCCAAAUGAU \\
2 & $1,864-1,886$ CCCUGUACAAUCGAAUCAA \\
3 & $431-453$ & CUGCGAUGAAGCCAUCUAU \\
NC & & CCUAAGGUUAAGUCGCCCUCG \\
\hline
\end{tabular}

Table II. Sequences of the primers used in for reverse transcription-quantitative polymerase chain reaction.

\begin{tabular}{lll}
\hline Primer & Direction & \multicolumn{1}{c}{ Sequence (5'-3') } \\
\hline PYGB & Forward & ACGCAGCAGCACTACTAC \\
& Reverse & TCGCAGGCATTCTGAAGG \\
GAPDH & Forward & CACCCACTCCTCCACCTTTG \\
& Reverse & CCACCACCCTGTTGCTGTAG \\
\hline
\end{tabular}

PYGB, Brain type glycogen phosphorylase.

Merck KGaA, Darmstadt, Germany at $4^{\circ} \mathrm{C}$. Lysed cells were centrifuged at $12,000 \mathrm{xg}$ for $15 \mathrm{~min}$ at $4^{\circ} \mathrm{C}$ and the supernatant was collected. Proteins were quantified using a Bicinchoninic Acid protein quantification kit (Thermo Fisher Scientific, Inc.) and run on a $12 \%$ SDS-PAGE (30 $\mu \mathrm{g} / \mathrm{lane})$. Proteins were then transferred to a nitrocellulose filter membrane (EMD Millipore, Billerica, MA, USA) electrophoretically and blocked with 5\% skim milk at room temperature for $1 \mathrm{~h}$. The membrane was then incubated with antibodies against PYGB (1:1,000; ab154969; Abcam, Cambridge, MA, USA), E-cadherin (1:1,000; cat. no. 14472; CST Biological Reagents Co., Ltd., Shanghai, China), Twist (1:500; ab175430), matrix metalloproteinase 9 (MMP9; 1:500; ab119906), MMP2 (1:1,000; ab92536; all Abcam), B-cell lymphoma 2 (Bcl-2; 1:400; sc-492), Bcl-2-associated X protein (Bax; 1:500; sc-493; both Santa Cruz Biotechnology, Inc., Dallas, TX, USA) and GAPDH (1:1,500; 5174, CST Biological Reagents Co., Ltd.) at $4^{\circ} \mathrm{C}$ overnight. Following further incubation with horseradish peroxidase-conjugated goat anti-mouse $(1: 1,000 ;$ A0206) or goat anti-rabbit $(1: 1,000 ;$ A0208) secondary antibodies (Beyotime Institute of Biotechnology, Shanghai, China) at room temperature for $1 \mathrm{~h}$, the blots were observed visually using enhanced chemiluminescence (Thermo Fisher Scientific, Inc.). ImageJ version 1.4.3 (National Institutes of Health, Bethesda, MD, USA) was used for densitometry analysis.

Cell proliferation assay. Cultured and transfected cells were trypsinized with $0.25 \%$ trypsin (Beijing Solarbio Science \& Technology Co., Ltd.), and diluted to $1-5 \times 10^{4}$ cells $/ \mathrm{ml}$. Each $1 \mathrm{ml}$ of cells was seeded into each well of 96 -well plates. Plates were incubated at $37^{\circ} \mathrm{C}$ for $0,24,48$ and $72 \mathrm{~h}$, hand mixed with $100 \mu \mathrm{l}$ DMEM containing 10\% Cell Counting kit (CCK)-8 reagent (Dojindo Molecular Technologies, Inc., Kumamoto, Japan), then 


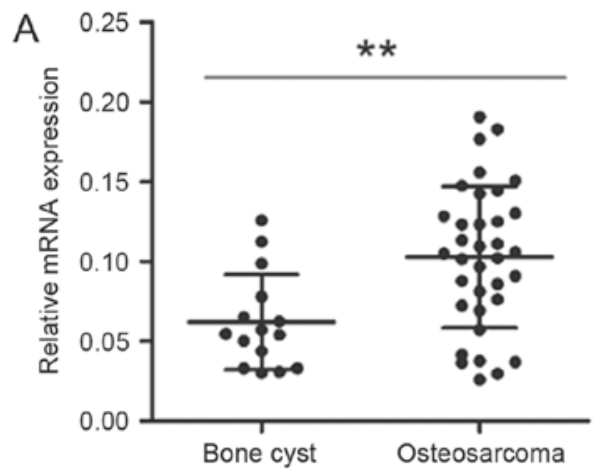

C

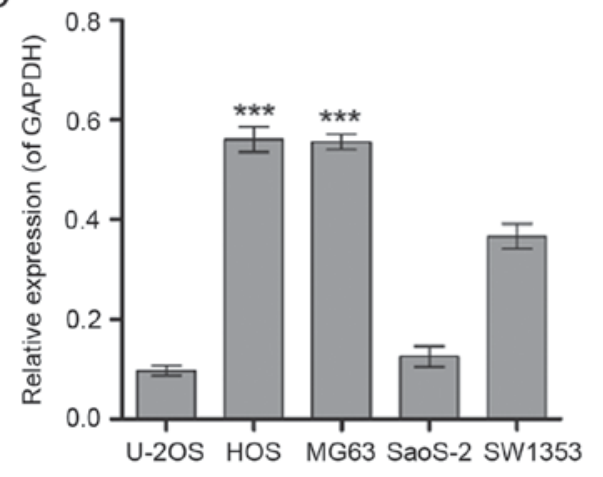

$\mathrm{E}$

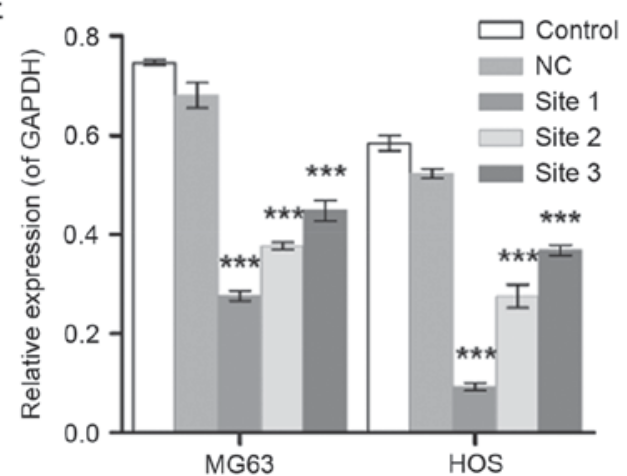

B

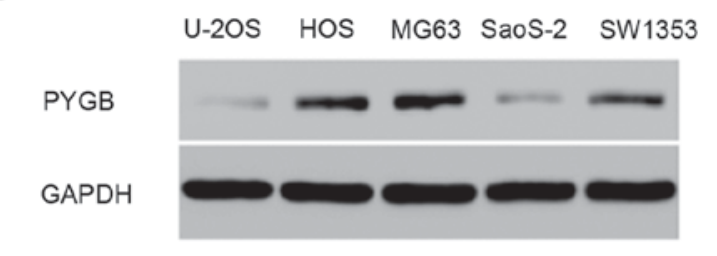

$\mathrm{D}$

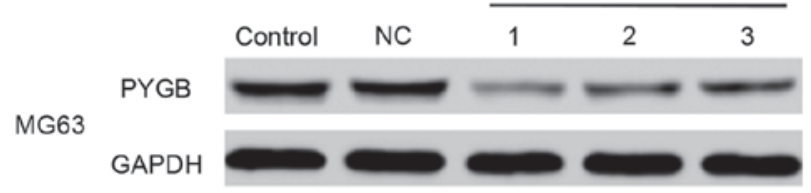

HOS

PYGB

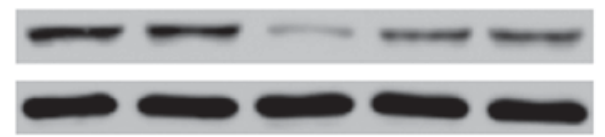

$\mathrm{F}$

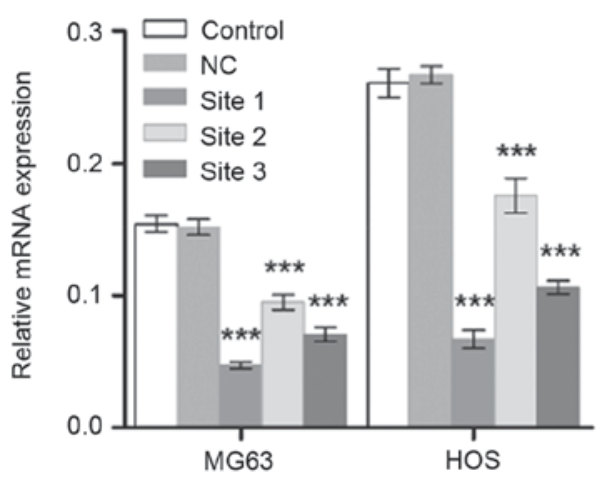

Figure 1. Screening of osteosarcoma cell lines with high expression level of PYGB. (A) RT-qPCR was used to measure the mRNA expression levels of PYGB in 15 bone cyst samples and 35 osteosarcoma samples. ${ }^{* *} \mathrm{P}<0.01$, as indicated. (B and C) The protein expression levels of PYGB in the human osteosarcoma cell lines U-20S, HOS, MG63, SaoS-2 and SW1353 were detected by western blot analysis. ${ }^{* * *} \mathrm{P}<0.001$ vs. U-2OS, SaoS-2 and SW1353. (D) Western blotting was also used to measure the PYGB protein expression in (E) MG63 and HOS cells following the transfection of PYGB siRNA at 3 interference sites. (F) In addition, the mRNA expression level of PYGB was also measured using RT-qPCR. ${ }^{* * *} \mathrm{P}<0.001$ vs. the NC group. Data are expressed as the mean \pm standard deviation ( $\mathrm{n}=3$ ). PYGB, Brain type glycogen phosphorylase; RT-qPCR, reverse transcription-quantitative polymerase chain reaction; NC, negative control; siRNA, small interfering RNA.

further incubated for $1 \mathrm{~h}$. Cell proliferation was evaluated using a spectrophotometer at the optical density of $450 \mathrm{~nm}$.

Cell apoptosis assay. Cultured and transfected cells were lightproof stained using an Annexin V-fluorescein isothiocyanate apoptosis detection kit (BD Biosciences, Franklin Lakes, NJ, USA) for $10 \mathrm{~min}$ at room temperature. Cell apoptosis was then evaluated using a flow cytometer (Accuri C6) and analyzed with Accuri C6 software, version 1.0.264 (both BD Biosciences).

Cell cycle assay. Cultured and transfected cells were fixed with $70 \%$ pre-cooled ethanol at $4{ }^{\circ} \mathrm{C}$ for $12 \mathrm{~h}$ following digestion with $0.25 \%$ trypsin and stained with propidium iodide at $4^{\circ} \mathrm{C}$ for $10 \mathrm{~min}$. DNA content was measured using a flow cytometer (Accuri C6) and analyzed with Accuri C6 software, version 1.0.264 (both BD Biosciences).

Cell invasion and migration assay using Transwell. Transfected cells were cultured in serum-free medium for $24 \mathrm{~h}$ prior to inoculation. Cells were digested with 0.25 trypsin (Beijing Solarbio Science \& Technology Co., Ltd.) and diluted to $1 \times 10^{5}$ cells/ml using DMEM (Hyclone; GE Healthcare Life Sciences) containing 1\% fetal bovine serum (FBS, Thermo Fisher Scientific, Inc.). In the cell invasion assay, the upper chamber was coated with $80 \mu \mathrm{l}$ Matrigel prior to the transfer of cells. A total of $0.5 \mathrm{ml}$ cell suspension was added into the upper chamber; the lower chamber was filled with $0.75 \mathrm{ml}$ DMEM containing 10\% FBS in each well. Following incubation at $37^{\circ} \mathrm{C}$ for $48 \mathrm{~h}$, cells were fixed with $1 \mathrm{ml} 4 \%$ methyl 

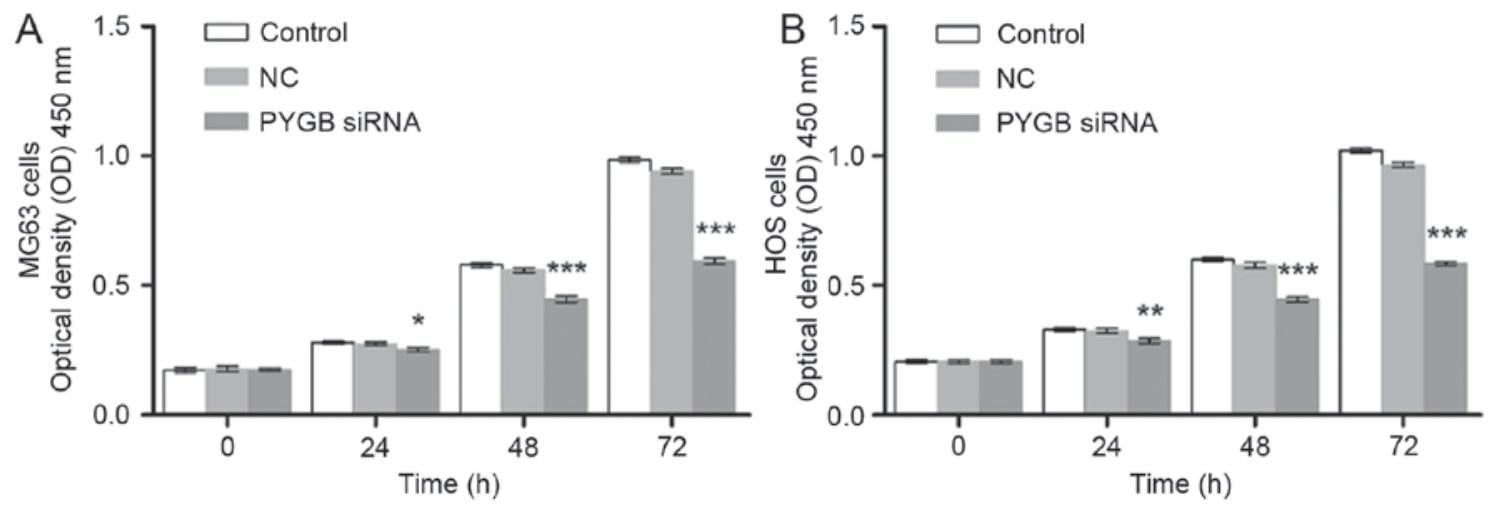

Figure 2. Effect of PYGB siRNA on the cell viability of the osteosarcoma cell lines MG63 and HOS. Following transfection with PYGB siRNA, the effect of PYGB siRNA on (A) the cell viability of MG63 cells and (B) the cell proliferation of HOS cells was evaluated by a Cell Counting kit-8 assay for 0, 24, 48 and $72 \mathrm{~h}$. Data are expressed as the mean \pm standard deviation $(\mathrm{n}=3) .{ }^{*} \mathrm{P}<0.05,{ }^{* * *} \mathrm{P}<0.01$ and ${ }^{* * * *} \mathrm{P}<0.001$ vs. the NC group. Data are expressed as the mean \pm standard deviation ( $\mathrm{n}=3$ ). PYGB, Brain type glycogen phosphorylase; NC, negative control; siRNA, small interfering RNA.

alcohol in each well at room temperature for $10 \mathrm{~min}$, and then stained with $1 \mathrm{ml} 0.5 \%$ crystal violet for at room temperature $30 \mathrm{~min}$. The 24-well plates were washed three times using $1 \mathrm{X}$ PBS and the number of invading cells were counted in 3 randomly selected fields using a light microscope (Olympus Corporation, Tokyo, Japan) under magnification, x200.

Statistical analysis. Experiments were repeated three times. Data were expressed as the mean \pm standard deviation and were analyzed using analysis of variance and Tukey's post hoc test. GraphPad Prism 5.0 software (GraphPad Software, Inc., La Jolla, CA, USA) was used to perform and analyze the data. RT-qPCR data was analyzed using ABI Prism 7300 SDS Software (Applied Biosystems; Thermo Fisher Scientific, Inc.). $\mathrm{P}<0.05$ was considered to indicate a statistically significant difference.

\section{Results}

Screening of an osteosarcoma cell line with a high expression level of PYGB. The gene expression level of PYGB was significantly different between normal (bone cyst; $n=15$ ) and tumor tissues from 35 patients with osteosarcoma ( $\mathrm{P}<0.01$; Fig. 1A). In addition, MG63 and HOS cells exhibited significantly higher expression levels of PYGB than the other osteosarcoma cell lines including U-20S, SaoS-2 and SW1353 detected by the western blot assay $(\mathrm{P}<0.001$; Fig. $1 \mathrm{~B}$ and $\mathrm{C})$. Therefore, the human osteosarcoma cell lines MG63 and HOS were selected for the subsequent experiments.

PYGB siRNA inhibits cell proliferation. The interference effect of PYGB siRNA, at 3 interference sites, on MG63 and HOS cells was determined using western blotting and RT-qPCR. The protein expression level of PYGB at all 3 interference sites declined significantly in MG63 and HOS cells $(\mathrm{P}<0.001$; Fig. 1D and E). The mRNA expression of PYGB also decreased significantly when compared with the negative control group (Fig. 1F), indicating the efficient interference ability of PYGB siRNA at interference site 1. In addition, CCK8 was employed to evaluate the cell viability of MG63 and HOS cells. As a result, the cell proliferation of PYGB siRNA transfected MG63 and HOS cells declined in a time-dependent manner
$(\mathrm{P}<0.05, \mathrm{P}<0.01$ and $\mathrm{P}<0.001$; Fig. 2$)$ indicating that siPYGB inhibited cell viability.

PYGB siRNA induces cell apoptosis. The apoptotic rate of MG63 and HOS cells was measured through flow cytometry following transfection for $48 \mathrm{~h}$. Apoptotic rate was calculated from the percentage of early apoptotic cells shown in the lower right quadrant (Fig. 3A and B). The results demonstrated that the apoptotic rate of MG63 cells increased to $22.33 \pm 2.14 \%$ in comparison with the $4.03 \pm 0.77 \%$ of the negative control group $(n=3 ; P<0.001$; Fig. 3A). Similarly, the apoptotic rate of HOS cells rose from $4.00 \pm 0.68$ to $20.37 \pm 1.68 \%$ ( $n=3$; $P<0.001$; Fig. $3 B$ ), indicating cell apoptosis was induced due to siPYGB, which in turn was suggestive of the important role of PYGB in osteosarcoma.

PYGB siRNA arrests cell cycle. Cell cycle distribution of MG63 and HOS cells was identified using flow cytometry following transfection for $48 \mathrm{~h}$. Cell cycle distribution was calculated according to the cell count at each stage (Fig. 3C and D). The results revealed that the percentage of PYGB siRNA treated MG63 cells in the G1 phase increased significantly from $49.74 \pm 1.54$ to $69.41 \pm 2.35 \%$ ( $n=3$; $P<0.01$; Fig. $3 C$ ) when compared with the negative control. While the percentage of cells in the $\mathrm{S}$ and $\mathrm{G} 2$ phases decreased from 21.04 \pm 2.59 to $14.15 \pm 0.98 \%(\mathrm{n}=3 ; \mathrm{P}<0.05)$ and from $25.62 \pm 0.64$ to $8.19 \pm 0.11 \%(\mathrm{n}=3 ; \mathrm{P}<0.01)$, respectively. In addition, a decline in cell count was also observed in the $\mathrm{S}$ phase of HOS cells from $21.62 \pm 0.99$ to $11.23 \pm 0.16 \%(\mathrm{n}=3 ; \mathrm{P}<0.001)$, and in the $\mathrm{G} 2$ phase from $27.03 \pm 0.89$ to $7.42 \pm 2.11 \%$ ( $n=3$; $P<0.001$; Fig. 3D). However, an increase in the percentage of G1 phase HOS cells was observed from $49.52 \pm 2.44$ to $75.95 \pm 0.64 \%$, suggesting that the cell cycle distribution was arrested in the G1 phase.

PYGB siRNA inhibits cell invasion and migration. The invasion and migration ability of MG63 and HOS cells was evaluated using a Transwell assay. As the results show in Fig. 4A and B, the invaded MG63 and HOS cells observed were fewer in number in the PYGB siRNA group than in the control and negative control groups. The cell count also markedly declined in the PYGB siRNA group in MG63 and HOS cells $(\mathrm{P}<0.01$ and $\mathrm{P}<0.001)$, indicating that there was significantly inhibited cell invasion in the two cell lines due 

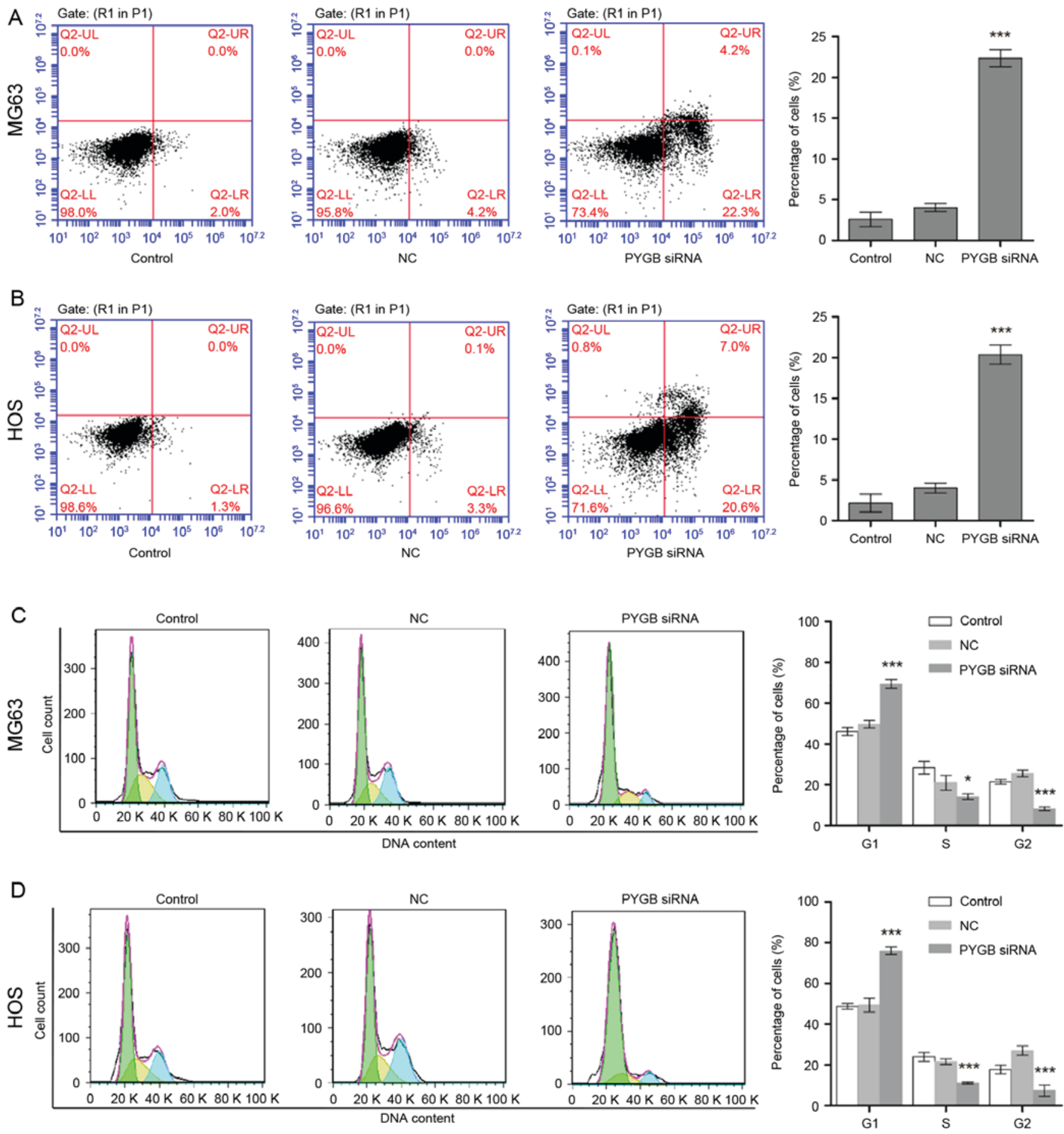

Figure 3. Effect of PYGB siRNA on cell apoptosis and the cell cycle in the osteosarcoma cell lines MG63 and HOS. (A) Cell apoptosis in MG63 cells was evaluated using flow cytometry following the transfection of PYGB siRNA for $48 \mathrm{~h}$. Early apoptotic cells were identified using Annexin V/propidium iodide double staining and are shown in the lower right quadrant. (B) Cell apoptosis induced by PYGB siRNA in HOS cells was also identified by flow cytometry. (C) The cell cycle distribution of MG63 cells following $48 \mathrm{~h}$ post-transfection with PYGB siRNA was detected using flow cytometry. (D) The cell cycle distribution of HOS cells was also evaluated using flow cytometry. " $\mathrm{P}<0.05$ and ${ }^{* * * *} \mathrm{P}<0.001$ vs. the NC group. Data are expressed as the mean \pm standard deviation $(\mathrm{n}=3)$. PYGB, Brain type glycogen phosphorylase; NC, negative control; siRNA, small interfering RNA.

to siPYGB. Suppressed migration rate of MG63 and HOS cells was also detected. A decreased number of migrated cells was observed in Fig. 4C and D, and a decline in cell count indicated that there was a significantly suppressed migration rate in MG63 and HOS cells (Fig. 4B and D; P<0.01).

PYGB siRNA suppresses cell viability through the Bcl/Caspase and cyclin dependent kinase (CDK1) signaling pathway.
Protein expression of the cell apoptosis associated proteins Bcl-2 and Bax, as well as the invasion and migration associated proteins E-cadherin, Twist, MMP9 and MMP2 were measured by western blotting (Fig. 5). The results revealed that Bax was significantly upregulated and Bcl-2 was significantly downregulated in MG63 and HOS cells, indicating that cell apoptosis was induced, and in turn, that the $\mathrm{Bcl} /$ Caspase signaling pathway was activated $(\mathrm{n}=3 ; \mathrm{P}<0.001)$. In addition, 

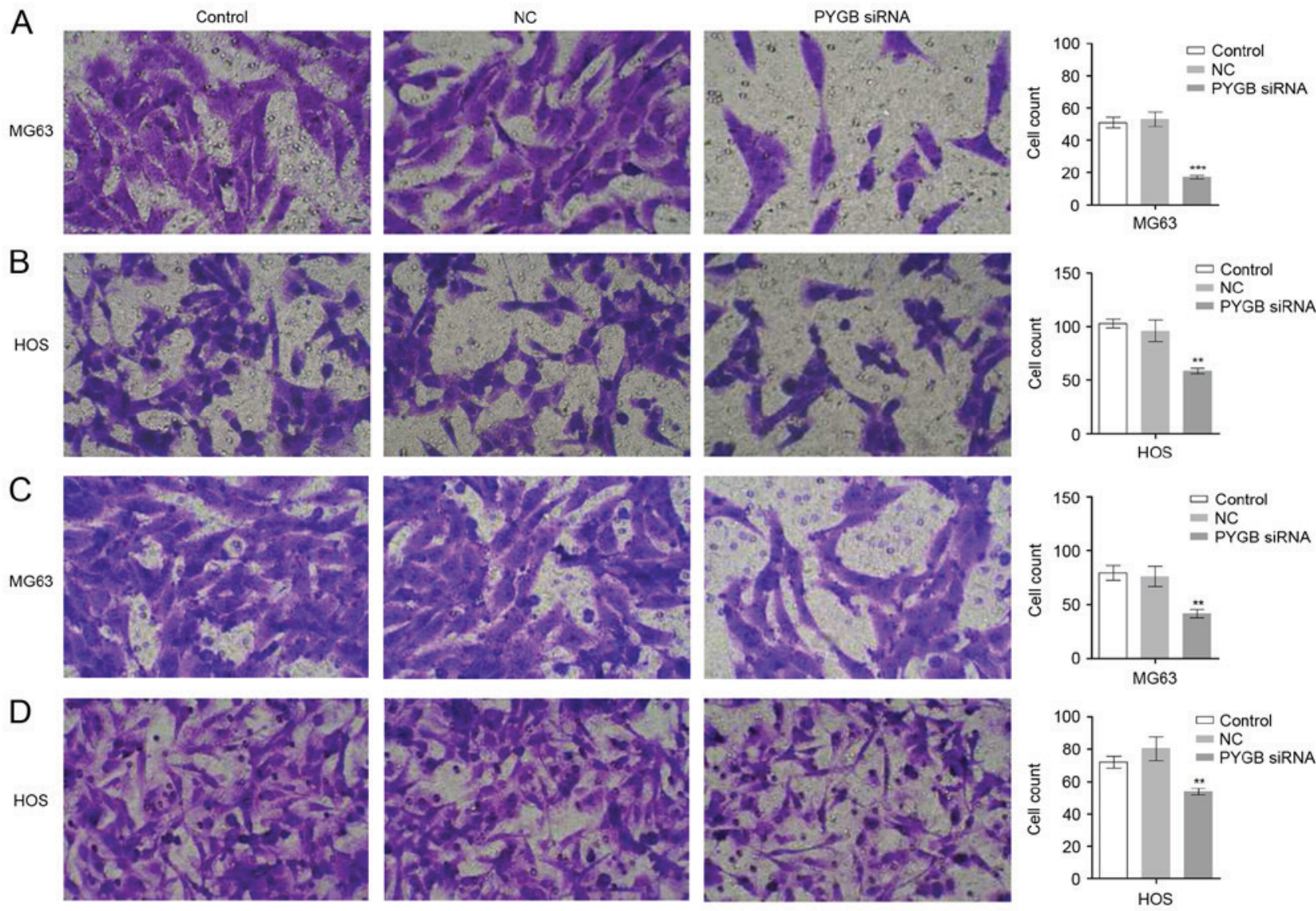

Figure 4. Effect of PYGB siRNA on the invasion and migration of osteosarcoma cell lines MG63 and HOS. (A and B) The invasive ability of MG63 and HOS cells was evaluated using a Transwell assay following $48 \mathrm{~h}$ post-transfection with PYGB siRNA. A smaller number of invaded MG63 and HOS cells were observed and counted in the PYGB siRNA group when compared with the control and NC groups. (C and D) Migrated MG63 and HOS cells were also identified by Transwell assay (magnification, $\mathrm{x} 200$ ). ${ }^{* * *} \mathrm{P}<0.01$ and ${ }^{* * * *} \mathrm{P}<0.001$ vs. the $\mathrm{NC}$ group. Data are expressed as the mean \pm standard deviation ( $\mathrm{n}=3$ ). $\mathrm{PYGB}$, Brain type glycogen phosphorylase; NC, negative control; siRNA, small interfering RNA.

the expression levels of Twist, MMP9 and MMP2 were significantly downregulated in MG63 and HOS cells when compared with the negative control $(\mathrm{n}=3 ; \mathrm{P}<0.05, \mathrm{P}<0.01$ and $\mathrm{P}<0.001)$. The protein levels of E-cadherin increased in MG63 and HOS cells following treatment with PYGB siRNA $(n=3 ; \mathrm{P}<0.001)$, indicating that cell invasion and migration was inhibited.

\section{Discussion}

In the present study, a greater expression of PYGB was detected in osteosarcoma samples when compared with bone cyst samples. Furthermore, as the regulatory effect of siPYGB on the cell proliferation, apoptosis, cell cycle, and cell invasion and migration of the osteosarcoma cell lines MG63 and HOS, the identification function of PYGB in osteosarcoma was demonstrated. Bax and $\mathrm{Bcl}-2$ were investigated in order to obtain further insight into the potential mechanisms involved in cell apoptosis induced by siPYGB in osteosarcoma cells. Bcl-2 belongs to the Bcl/B-cell leukemia-2 family and is antagonistic towards $\mathrm{Bax}(18,19)$. Bcl-2 has an anti-apoptosis function that inactivates the pro-apoptotic proteins Caspase-3, Bax and Bcl-2 antagonist/killer, and inhibits the release of apoptosis-promoting substances from the mitochondria. In agreement with the cellular function of Bcl-2 and Bax, induced cell apoptosis in PYGB siRNA treated MG63 and HOS cells was accompanied by increased Bax and declined Bcl-2 protein levels, which indicated that apoptosis in siPYGB transfected cells was induced via the $\mathrm{Bcl} /$ Caspase signaling pathway; this in turn suggested the vital role of PYGB in the survival of osteosarcoma cells.

Tumor metastasis involves epithelial-mesenchymal transition (EMT) and mesenchymal-epithelial transition (MET) (20). MET is coupled with the degradation of the extracellular matrix (ECM) by the MMP family $(21,22)$. EMT is accompanied by the degradation of the basement membrane, which is normally responsible for tissue organization maintenance; cell structural support is an essential step for tumor metastasis (23). Type IV collagen is the most abundant component of the basement membrane, and can easily be degraded by MMP2 and MMP9 $(21,22)$. The declined expression levels of MMP2 and MMP9 in the present study, suggested there may be stabilization of the ECM and a decreased invasion rate of osteosarcoma cells.

E-cadherin belongs to the cadherin superfamily, which serve an important role in the switch between EMT and MET. Epithelial cells are held together tightly via a crucial type of cell to cell adhesion. It has been reported to act as an invasion suppressor gene in pre-invasive lobular breast carcinoma $(24,25)$. Mutations in this gene have been associated with gastric, breast, colorectal, thyroid and ovarian cancer. Loss of E-cadherin expression leads to the release 
A

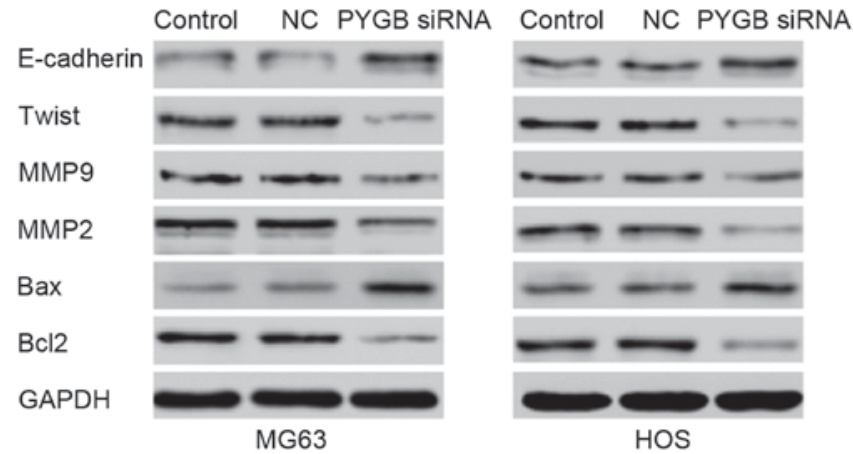

B

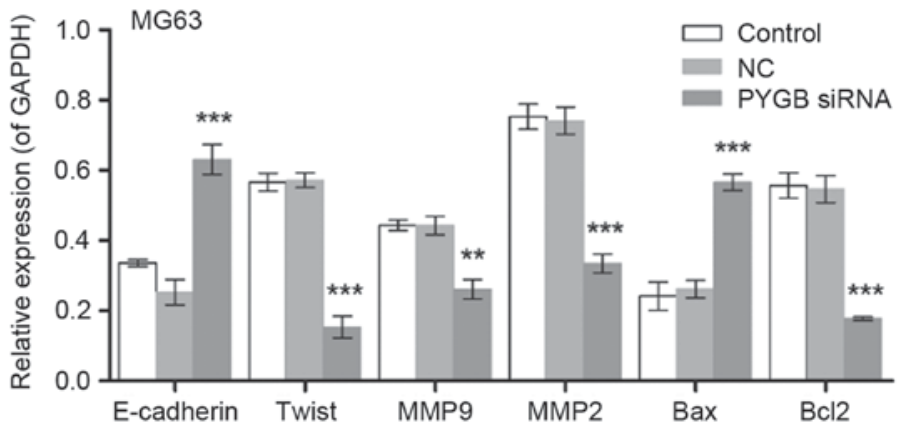

C

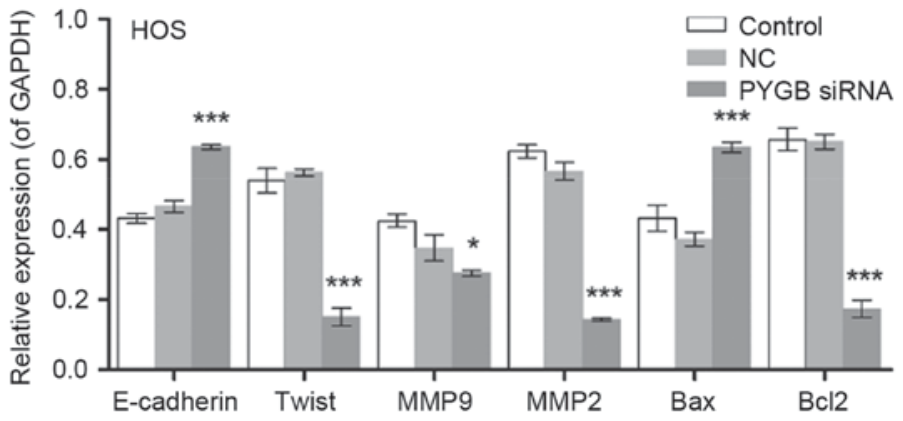

Figure 5. Effect of PYGB siRNA on the expression of E-cadherin, Twist, MMP9, MMP2, Bax and Bc12 in the osteosarcoma cell lines MG63 and HOS. (A) The blots show the results of western blot analysis. The protein expression levels in (B) MG63 and (C) HOS cells were measured by western blot analysis $48 \mathrm{~h}$ following treatment with PYGB siRNA. ${ }^{*} \mathrm{P}<0.05,{ }^{* *} \mathrm{P}<0.01$ and ${ }^{* * *} \mathrm{P}<0.001$ vs. the $\mathrm{NC}$ group. Data are expressed as the mean \pm standard deviation ( $\mathrm{n}=3$ ). $\mathrm{PYGB}$, Brain type glycogen phosphorylase; NC, negative control; siRNA, small interfering RNA; MMP, matrix metalloproteinase; Bcl2, B-cell lymphoma 2; Bax, Bcl-2-associated X protein.

of $\beta$-catenin into the cytoplasm and results in the expression of EMT-inducing transcription factors (26). However, cancer cells in the mesenchymal state may undergo MET in certain favorable microenvironments following migration to novel sites by E-cadherin during metastasis (27). In addition, upregulated E-cadherin induced cell-cell adhesions between cancer cells at differentiated epithelial cell features in order to form a novel tumor lesion (28). Twist is a highly conserved transcription factor that belongs to the alkaline spiral-ring-spiral protein family. In contrast to E-cadherin, it serves an important role in the occurrence and development of embryos as a key regulation factor in the process of epithelium-interstitial change (29). Twist was demonstrated to be a potential cancer gene protein that promotes the occurrence, invasion, metastasis and tolerance, and inhibits the apoptosis, of tumor cells (30). In the present study, the upregulation of E-cadherin and downregulation of Twist in the siPYGB group corresponded to the suppressed invasion and migration rate, which indicated that there may be tight cell-cell adhesion and relocation of tumor cells during the metastasis of MG63 and HOS cells. In view of the decreased Twist and increased E-cadherin expression levels, the cell invasion and migration of the human osteosarcoma cell lines MG63 and HOS may be inhibited by PYGB siRNA via the CDK1 signaling pathway.

In conclusion, in the present study PYGB interference resulted in inhibited cell proliferation, arrested cell cycle, induced cell apoptosis, and suppressed cell invasion and migration, potentially via the Caspase/Bcl and CDK1 signaling pathway. Thus, the significant inhibitory effect of PYGB siRNA on the cell viability of the human osteosarcoma cell lines MG63 and HOS was demonstrated. The findings of the present study suggested that PYGB may considered as a therapeutic target for osteosarcoma.

\section{Acknowledgements}

Not applicable. 


\section{Funding}

No funding was received.

\section{Availability of data and materials}

All data generated or analyzed during this study are included in this published article.

\section{Authors' contributions}

SZ, JL and WJ conceived and designed the study. SZ, YCZ, YYZ, YY and LW performed the experiments. SZ and WJ wrote the manuscript. All authors read and approved the manuscript.

\section{Ethics approval and consent to participate}

The study protocol was approved by the independent Ethical Committee of Zhongnan Hospital of Wuhan University (Hubei, China) and written informed consent was obtained from all participants.

\section{Consent for publication}

Not applicable.

\section{Competing interests}

The authors declare that they have no competing interests.

\section{References}

1. Anoop T, Geetha N, Babanrao SA and Jayasree K: Primary osteosarcoma of rib mimicking lung mass with secondary aneurysmal bone cyst formation. J Thorac Oncol 9: 738-739, 2014.

2. Do T, Renker EK and Weber MA: Simulation of teleangiectactic osteosarcoma by aneurysmatic bone cyst. Orthopade 42: 1067-1070, 2013 (In German).

3. Janevska V, Spasevska L, Samardziski M, Nikodinovska V, Zhivadinovik J and Trajkovska E: From aneurysmal bone cyst to telangiectatic osteosarcoma with metastasis in inguinal lymph nodes-Case report. Med Pregl 68: 127-132, 2015.

4. Aung L, Gorlick RG, Shi W, Thaler H, Shorter NA, Healey JH, Huvos AG and Meyers PA: Second malignant neoplasms in long-term survivors of osteosarcoma. Cancer 95: 1728-1734, 2002.

5. Bacci G, Ferrari C, Longhi A, Ferrari S, Forni C, Bacchini P Palmerini E, Briccoli A, Pignotti E, Balladelli A and Picci P. Second malignant neoplasm in patients with osteosarcoma of the extremities treated with adjuvant and neoadjuvant chemotherapy. J Pediatr Hematol Oncol 28: 774-780, 2006.

6. Nagarajan R, Kamruzzaman A, Ness KK, Marchese VG, Sklar C, Mertens A, Yasui Y, Robison LL and Marina N: Twenty years of follow-up of survivors of childhood osteosarcoma: A report from the Childhood Cancer Survivor Study. Cancer 117: 625-634, 2011

7. Jaffe N: Historical perspective of the treatment of osteosarcoma: An interview with Dr Norman Jaffe. Interview by Margaret pearson. J Pediatr Oncol Nurs 15: 90-94, 1998.

8. Longhi A, Ferrari S, Tamburini A, Luksch R, Fagioli F, Bacci G and Ferrari $\mathrm{C}$ : Late effects of chemotherapy and radiotherapy in osteosarcoma and ewing sarcoma patients: The Italian Sarcoma Group Experience (1983-2006). Cancer 118: 5050-5059, 2012.

9. Luetke A, Meyers PA, Lewis I and Juergens H: Osteosarcoma treatment-where do we stand? A state of the art review. Cancer Treat Rev 40: 523-532, 2014.
10. Newgard CB, Hwang PK and Fletterick RJ: The family of glycogen phosphorylases: Structure and function. Crit Rev Biochem Mol Biol 24: 69-99, 1989.

11. Newgard CB, Littman DR, van Genderen C, Smith M and Fletterick RJ: Human brain glycogen phosphorylase. Cloning, sequence analysis, chromosomal mapping, tissue expression, and comparison with the human liver and muscle isozymes. J Biol Chem 263: 3850-3857, 1988.

12. Philips KB, Kurtoglu M, Leung HJ, Liu H, Gao N, Lehrman MA, Murray TG and Lampidis TJ: Increased sensitivity to glucose starvation correlates with downregulation of glycogen phosphorylase isoform PYGB in tumor cell lines resistant to 2-deoxy-D-glucose. Cancer Chemother Pharmacol 73: 349-361, 2014.

13. Shimada S, Maeno M, Akagi M, Hatayama I, Sato T and Sato K: Immunohistochemical detection of glycogen phosphorylase isoenzymes in rat and human tissues. Histochem J 18: 334-338, 1986.

14. Barbosa AJ and Castro LP: BGP expression in gastric epithelium and early gastric cancer. Gastric Cancer 5: 123-124, 2002.

15. Shimada S, Shiomori K, Honmyo U, Maeno M, Yagi Y and Ogawa M: BGP expression in gastric biopsies may predict the development of new lesions after local treatment for early gastric cancer. Gastric Cancer 5: 130-136, 2002.

16. Tashima S, Shimada S, Yamaguchi K, Tsuruta J and Ogawa M: Expression of brain-type glycogen phosphorylase is a potentially novel early biomarker in the carcinogenesis of human colorectal carcinomas. Am J Gastroenterol 95: 255-263, 2000.

17. Livak KJ and Schmittgen TD: Analysis of relative gene expression data using real-time quantitative PCR and the 2(-Delta Delta $\mathrm{C}(\mathrm{T}))$ method. Methods 25: 402-408, 2001.

18. Kirkin V, Joos S and Zörnig M: The role of Bcl-2 family members in tumorigenesis. Biochim Biophys Acta 1644: 229-249, 2004.

19. Manion MK and Hockenbery DM: Targeting Bcl-2 related proteins in cancer therapy. Cancer Biol Ther 2 (4 Suppl 1): S105-S114, 2003.

20. Waerner T, Alacakaptan M, Tamir I, Oberauer R, Gal A, Brabletz T, Schreiber M, Jechlinger M and Beug H: ILEI: A cytokine essential for EMT, tumor formation, and late events in metastasis in epithelial cells. Cancer Cell 10: 227-239, 2006.

21. Halbleib JM and Nelson WJ: Cadherins in development: Cell adhesion, sorting, and tissue morphogenesis. Genes Dev 20: 3199-3214, 2006

22. Page-McCaw A, Ewald AJ and Werb Z: Matrix metalloproteinases and the regulation of tissue remodelling. Nat Rev Mol Cell Biol 8: 221-233, 2007.

23. Thiery JP, Acloque H, Huang RY and Nieto MA: Epithelial-mesenchymal transitions in development and disease. Cell 139: 871-890, 2009

24. Gould Rothberg BE and Bracken MB: E-cadherin immunohistochemical expression as a prognostic factor in infiltrating ductal carcinoma of the breast: A systematic review and meta-analysis. Breast Cancer Res Treat 100: 139-148, 2006.

25. Shibata T and Hirohashi S: E-cadherin cell adhesion system in human cancer. Seikagaku 78: 647-656, 2006 (In Japanese).

26. Tycko B, Li CM and Buttyan R: The Wnt/beta-catenin pathway in Wilms tumors and prostate cancers. Curr Mol Med 7: 479-489, 2007.

27. Onder TT, Gupta PB, Mani SA, Yang J, Lander ES and Weinberg RA: Loss of E-cadherin promotes metastasis via multiple downstream transcriptional pathways. Cancer Res 68: 3645-3654, 2008.

28. Christofori $\mathrm{G}$ and Semb $\mathrm{H}$ : The role of the cell-adhesion molecule E-cadherin as a tumour-suppressor gene. Trends Biochem Sci 24: 73-76, 1999.

29. Leptin M: Twist and snail as positive and negative regulators during Drosophila mesoderm development. Genes Dev 5: 1568-1576, 1991.

30. Vesuna F, van Diest P, Chen JH and Raman V: Twist is a transcriptional repressor of E-cadherin gene expression in breast cancer. Biochem Biophys Res Commun 367: 235-241, 2008.

This work is licensed under a Creative Commons Attribution-NonCommercial-NoDerivatives 4.0 International (CC BY-NC-ND 4.0) License. 